\title{
Effects of time step size on the simulation of tropical climate in NCAR-CAM3
}

\author{
Saroj K. Mishra $\cdot$ Sandeep Sahany
}

Received: 18 January 2010/ Accepted: 9 January 2011/Published online: 28 January 2011

(c) The Author(s) 2011. This article is published with open access at Springerlink.com

\begin{abstract}
This paper describes the effects of time step on the simulation of tropical climate in the NCAR-Community Atmosphere Model version 3 (CAM3). A set of multiyear integrations are carried out in a real-planet framework using actual land-ocean distribution and observed sea surface temperature. Over the tropics there is an increase in total rainfall with a decrease in time step size. Using a lower time step, there is a decrease in the convective component of rainfall, however, the stratiform component increases, and more than compensates the decrease in the former, thus leading to a higher total rainfall. A decrease in time step leads to an increase in the frequencies of moderate, and heavy rainfall categories, which is responsible for the increase in time mean total rainfall over the tropics. Also, the spatial distribution of rainfall becomes more realistic during both summer and winter seasons. In regard to the simulation of equatorial waves, it is found that a lower time step leads to a reduction in the speed of Kelvin waves. The latent heating profile becomes more bottomheavy with a reduction in time step size, which potentially leads to slower Kelvin waves. Finally, additional experiments conducted in an aqua-planet framework show a consistent and systematic change in the analyzed variables
\end{abstract}

S. K. Mishra $(\bowtie)$

Institute for Mathematics Applied to Geosciences (IMAGe),

National Center for Atmospheric Research (NCAR),

1850, Table Mesa Drive, Boulder, CO 80305, USA

e-mail: saroj@ucar.edu

\section{S. K. Mishra}

Department of Computer Science,

University of Colorado, Boulder, CO, USA

\section{S. Sahany}

Department of Atmospheric and Oceanic Sciences,

University of California, Los Angeles, Los Angeles, CA, USA with change in time step, and hence confirm the robustness of the results across modeling frameworks.

Keywords Time step - Dynamical core - Tropical climate $\cdot$ Equatorial waves $\cdot$ Rainfall $\cdot$ Precipitation

\section{Introduction}

The atmospheric general circulation model (AGCM) is typically represented with two sub-modules: one representing the dry and adiabatic atmosphere and other the diabatic processes. The sub-module dealing with the numerical solution to the dry adiabatic primitive equations of the atmosphere is referred to as the dynamical core, while the one dealing with the diabatic processes is referred to as the physics module. The dynamical core governs the time step size used for numerical integrations, based on the CourantFriedrichs-Lewy (CFL) criterion (Courant et al. 1967). The longer the time step size the lesser is the computational cost for a given simulation. The general rule of CFL criterion is that the numerical domain of dependence must include the analytical domain of dependence to assure that the numerical scheme can access the information required to form the solution. In the past decades, several dynamical cores have been developed to increase the computational efficiency of models. This is achieved by lengthening the maximum permissible time step size. The modeling community prefers to use computationally more efficient numerical schemes for their simulations, with the underlying assumption that the simulations are relatively independent of the time step size. However, the impact of time step is not so adequately studied and is poorly understood.

With relatively large time step and high vertical resolutions near the surface, the explicit solution of the mass 
flux equations in the convective scheme can only remain stable if the local CFL condition is satisfied (Jakob and Pier Siebesma 2003). This condition implies a maximum mass flux in a given layer that is defined as in Eq. 1:

$M_{\mathrm{b}}=d p /(g \times d t)$

where $d p$ is the depth of the model layer, $g$ is the acceleration due to gravity, and $d t$ is the time step size. Hence, if the models increase the time step size and refine the vertical resolutions with explicit solver for mass flux scheme, the CFL criterion will be violated. Due to non-linear numerical stability, spurious numerical oscillations may occur with large time step size (Teixeira et al. 2007). Vertical turbulent mixing in climate model is generally parameterized using a k-diffusion approach, where $\mathrm{k}$ depends on the mean variables. This method of parameterization creates a system of non linear diffusion equations with numerical stability problems (Girard and Delage 1990; Beljaars 1991; Teixeira 1999), and this is one of the reasons why the time step of climate models can not be significantly increased (Williamson 1996).

Williamson and Olson (2003; hereafter WO03) examined the impact of dynamical core on model simulations in the National Center for Atmospheric Research (NCAR) Community Climate Model version 3 (CCM3) and found significant sensitivity. They used the Neale and Hoskins (2000) standard aqua-planet test suite with two variants of the CCM3. The two variants differed in the formulation of dynamical cores, one was Eulerian (EUL) and the other was semi-Lagrangian (SLD). WO03 showed that there are many differences between the two dynamical cores; time step size being one of them. They carried out numerical experiments to examine this and found that the primary reason behind the impact of the dynamical core on model simulations is the time step. They further showed that the sensitivity is not due to the different time truncation errors, but the time step of the parameterization suite. Williamson (2008) showed a strong sensitivity of zonal average equatorial precipitation to time step in the CCM3 aqua-planet.

In a previous study (Mishra et al. 2008), we showed that the time step affects the simulated intensity of inter tropical convergence zone (ITCZ) in an aqua-planet. The root cause and pathway of the impact was explained from the spin up period of simulations. The impact could be traced to the very first time step of model integration, which further evolves during the subsequent $36 \mathrm{~h}$, and then persists thereafter. The model updates the state variables, as shown in Eq. 2, where, $\mathrm{n}$ stands for the time instant.

$(\text { state })^{n+1}=(\text { state })^{n}+(\text { tendency })^{n} \times$ time step size

According to the current computational flow, the state variables are updated after computation of each parameterization scheme, and then the updated variables are used for the computation of tendencies in the next parameterization scheme. Mishra et al. (2008) can be referred for a more detailed illustration of the computational sequences used in the model. We showed that the impact of time step originated from the deep convection scheme, which subsequently affected the model solution through non-linear interactions.

We now carry out this study in a real-planet framework to explore the effects in more details, and focus primarily on the simulation of rainfall, since it plays a major role in the interactions of the dynamics and the thermodynamics of the climate system. For this, a realistic model configuration is used with earth-like land-ocean distribution, topography, observed sea surface temperatures with seasonal cycle, and fully interactive physics. To carry out this study, we use the Community Atmosphere Model version 3 (CAM3) developed at NCAR.

Hurrell et al. (2006) examined the dynamical simulation of CAM3 and showed that the model reproduces the basic observed patterns of the pressure field at sea level. However, there exists a tendency for the tropical precipitation maxima to remain in the northern hemisphere throughout the year. Also, the simulated precipitation along the equator tends to be less than that indicated by satellite estimates. In another relevant study, Rasch et al. (2006) investigated the simulation of tropical transient activities in CAM3, and showed that the ratio of stratiform to convective rainfall is too low in the model. Precipitation variance was underestimated on time scales from a few hours to 10 days, compared to observations over oceans. Hack et al. (2006) examined the impact of horizontal resolution on the model simulations and showed robust systematic improvements with higher horizontal resolution. Using CAM3, Sahany and Nanjundiah (2008) investigated the impact of convective downdrafts on tropical climate, and Mishra and Srinivasan (2010) showed the dependence of model simulation on convective relaxation time scale. These studies document the fidelity of CAM3 in simulating the climate and its dependence on various model components. However, none of the above studies investigate the effects of time step size in a real-planet framework, hence, in the current work we explore this important yet poorly understood aspect of model sensitivity.

The paper is organized as follows: in Sect. 2 we present a description of the model and numerical experiments, followed by discussion of the results in Sect. 3. First, the effects of time step on the area-averaged time mean rainfall and its associated state variables are discussed, then we show the impact on the simulated intensity and frequency of rainfall, spatial distribution of rainfall, effects on equatorial waves, and then the consistency of the results. Finally, discussions and concluding remarks follow in Sect. 4. 


\section{Model and experiments}

In this section, we present the details pertaining to the model used, numerical experiments conducted, and various datasets used for the validation of model outputs.

\subsection{About the model}

The NCAR-CAM3 has been described in details in Collins et al. (2004). In the model, precipitation is computed in three steps. In the first step, the deep convective precipitation is calculated (using the Zhang and McFarlane (1995) deep convection scheme (ZM)). The updraft ensembles in $\mathrm{ZM}$ are deep penetrative in nature, with roots in the planetary boundary layer and penetrate into the upper troposphere until their neutral buoyancy levels. The top of the "shallowest" of the convective plumes is assumed to be no lower than the height of the minimum in saturated moist static energy (typically in the mid-troposphere). In the second step, the shallow convective precipitation is estimated using the formulation of Hack (1994). The Hack scheme uses a simple cloud model based on triplets in which convective instability is assessed for three adjacent layers in the vertical. If a parcel of air in the lower layer is more buoyant than one in the middle layer, adjustment occurs. In the third step, the prognostic cloud water parameterization scheme (RKZ) of Rasch and Kristjansson (1998) updated by Zhang et al. (2003) is used for the estimation of large scale precipitation, which is also called stratiform precipitation. Separate evolution equations have been included for the liquid and ice phase condensate. Condensed water detrained from shallow and frontal convection can form either precipitation or additional stratiform cloud water. Convective precipitation can evaporate into its environment at a rate determined from Sundqvist (1988). Equations governing cloud condensate include advection and sedimentation of cloud droplets and ice particles. The settling velocities for liquid and ice-phase constituents are computed separately as functions of particle size characterized by the effective radius. Small ice particles are assumed to fall like spheres according to the Stokes equation. With the increase in size of the ice particles, there is a smooth transition to a different formulation for fall speeds following Locatelli and Hobbs (1974). In the case of liquid drops, fall velocities are calculated using Stokes equation for the entire range of sizes. All the parameterizations except the radiation parameterization are called during every time step. The frequency of calling the radiation parameterization is $1 \mathrm{~h}$ and is independent of the time step size used in the dynamical core.

For stand-alone integrations of CAM3, sea surface temperatures and sea ice concentrations are required as lower boundary conditions for the model. These datasets prescribe monthly midpoint mean values of sea surface temperatures (SSTs) and ice concentration for the period 1950 through 2001. The datasets are blended products that combine the global Hadley Center Sea Ice and Sea Surface Temperature (HadISST) dataset (Rayner et al. 2003) for years up to 1981 and the Reynolds et al. (2002) dataset after 1981. In the parameterization for orographically generated gravity waves, the sub-grid-scale variation of orography determines the streamline displacement and the length scale for averaging other parameters in the wave source function taken from McFarlane (1987). A four-layer representation of the sea ice, used by the thermodynamic sea ice model, simulates the snow depth, surface temperature, ice thickness, ice fractional coverage, and energy exchange. Based on the source of sea surface temperatures it can be operated in two modes i.e., data ocean model and slab ocean model. If SSTs are obtained from a boundary dataset, then ice coverage is also obtained from a corresponding dataset. The ice thickness is set to $2 \mathrm{~m}$ in the Northern Hemisphere and $0.5 \mathrm{~m}$ in the Southern Hemisphere. In this case, the purpose of the sea ice model is to compute energy fluxes between ice and the overlying atmosphere. If SSTs are computed using the slab ocean model, this model calculates the ice coverage and thickness as well. In this study, we use the data ocean model.

\subsection{Experiments}

Two multi-year numerical experiments were performed using the Atmospheric Model Intercomparison Project (AMIP) protocol with observed SST. One simulation was conducted with $60 \mathrm{~min}$ time step size (SLD60) and another with 5 min time step (SLD5). Both the simulations used the semi-Lagrangian dynamical core. The spectral resolution used was T63 and the physical resolution was $128 \times 64$, with 26 levels in the vertical. The model parameters and physics package was same for all the simulations. The maximum permissible time step of SLD for the abovementioned spectral resolution is $60 \mathrm{~min}$. On the other hand, the cumulus scheme of the model may not work below 5 min time step size, and hence, we choose the above two time steps for this study. The initial condition used was generated for 01 Jan 1979. The model computed and predicted the soil moisture and snow cover. Similarly, an additional 10-year long simulation was carried out with 20 min time step size (SLD20) to verify the consistency of the effects across timesteps. The model performance is evaluated by comparing the output fields with observational and re-analysis data. For rainfall evaluation, the Climate Prediction Center (CPC) Merged Analysis of Precipitation (CMAP) has been used (Xie and Arkin 1996). In addition, Outgoing Longwave Radiation (OLR) data from NOAA polar-orbiting satellites (Liebmann and Smith 
1996) are used for the examination of the simulated equatorial waves. Furthermore, a set of numerical experiments has been conducted using an aqua-planet configuration of NCAR CAM3 to examine the robustness of the effects. Four simulations were performed, first with $60 \mathrm{~min}$ (SLD60), second with $30 \mathrm{~min}$ (SLD30), third with $20 \mathrm{~min}$ (SLD20), and fourth with $5 \mathrm{~min}$ (SLD5) for this purpose. Zonally symmetric SST similar to the control SST of Neale and Hoskins (2000) have been used as boundary condition. The solar forcing with diurnal cycle was set for equinoctial conditions (21st March) in the radiation code. The initial condition for all simulations was from a previous aquaplanet simulation. All the simulations were performed for 18 months, and the last 12 months were considered for analysis.

\section{Results from the numerical experiments}

\subsection{Mean rainfall and its associated state variables}

Here we describe the impact of time step on the time mean, area averaged rainfall and its associated state variables in the tropics $(0-360 \mathrm{E}$ and $30 \mathrm{~S}-30 \mathrm{~N})$. The time mean values were computed by averaging all months of the 10-year integration period. In Fig. 1, we show the state variables from the model runs with time step size of $60 \mathrm{~min}$ (control case) and $5 \mathrm{~min}$ (experiment). It is seen from the figure that a decrease in time step leads to an increase in total rainfall (TRF). Figure 1b, c show the convective and large-scale components of the TRF, respectively. With the decrease in time step, there is a reduction in the convective rainfall (CRF) and enhancement in large-scale rainfall (LRF). The increase in LRF outweighs the decrease in CRF and thus resulting in an overall increase in TRF. Increase in total rainfall over a region can be caused by interplay between the surface evaporation and moisture divergence and hence we further analyze these diagnostics. It can be seen from Fig. 1d, e, that both surface evaporation and large-scale moisture divergence increase with decrease of time step. Increase of surface evaporation leads to an increase in the precipitable water (see Fig. 1f). The model computes the surface evaporation by using the wind strength and moisture deficit at the $1^{\text {st }}$ model level. The wind speed at the first model level is found to be higher with a lower time step (see Fig. 1g), while the corresponding specific humidity is found to be lower (see Fig. 1h). It can be seen from the figure that the magnitude of change in wind speed is more than that of specific humidity at the 1st model level. Thus, the primary reason behind the enhancement in surface evaporation with reduction in time step is the increase in low-level wind speed. Another intriguing feature is the reduction in CRF with a lower time step, as can be seen from Fig. 1b. Since CRF is directly associated with the atmospheric instability, we further examine the amount of convective available potential energy (CAPE) available for deep convection in the two cases. It can be seen from Fig. $1 \mathrm{i}$ that there is a decrease in CAPE with decrease in time step size, and this explains the corresponding reduction in CRF.
Fig. 1 Area averaged $(0 \mathrm{E}-$ $360 \mathrm{E}$ and $30 \mathrm{~S}-30 \mathrm{~N}$ ), time mean (all months of 10 years) quantities for SLD60 and SLD5. a Total rainfall $(\mathrm{mm} /$ day $)$, b convective rainfall ( $\mathrm{mm} /$ day), c large-scale rainfall ( $\mathrm{mm} /$ day), d surface evaporation (mm/day), e large-scale moisture divergence $(\mathrm{mm} /$ day), f precipitable water $\left(\mathrm{kg} / \mathrm{m}^{2}\right)$, g magnitude of wind at the 1st model level $(\mathrm{m} / \mathrm{s}), \mathbf{h}$ specific humidity at the 1 st model level $(\mathrm{g} / \mathrm{kg})$, and i CAPE $(\mathrm{J} / \mathrm{kg})$
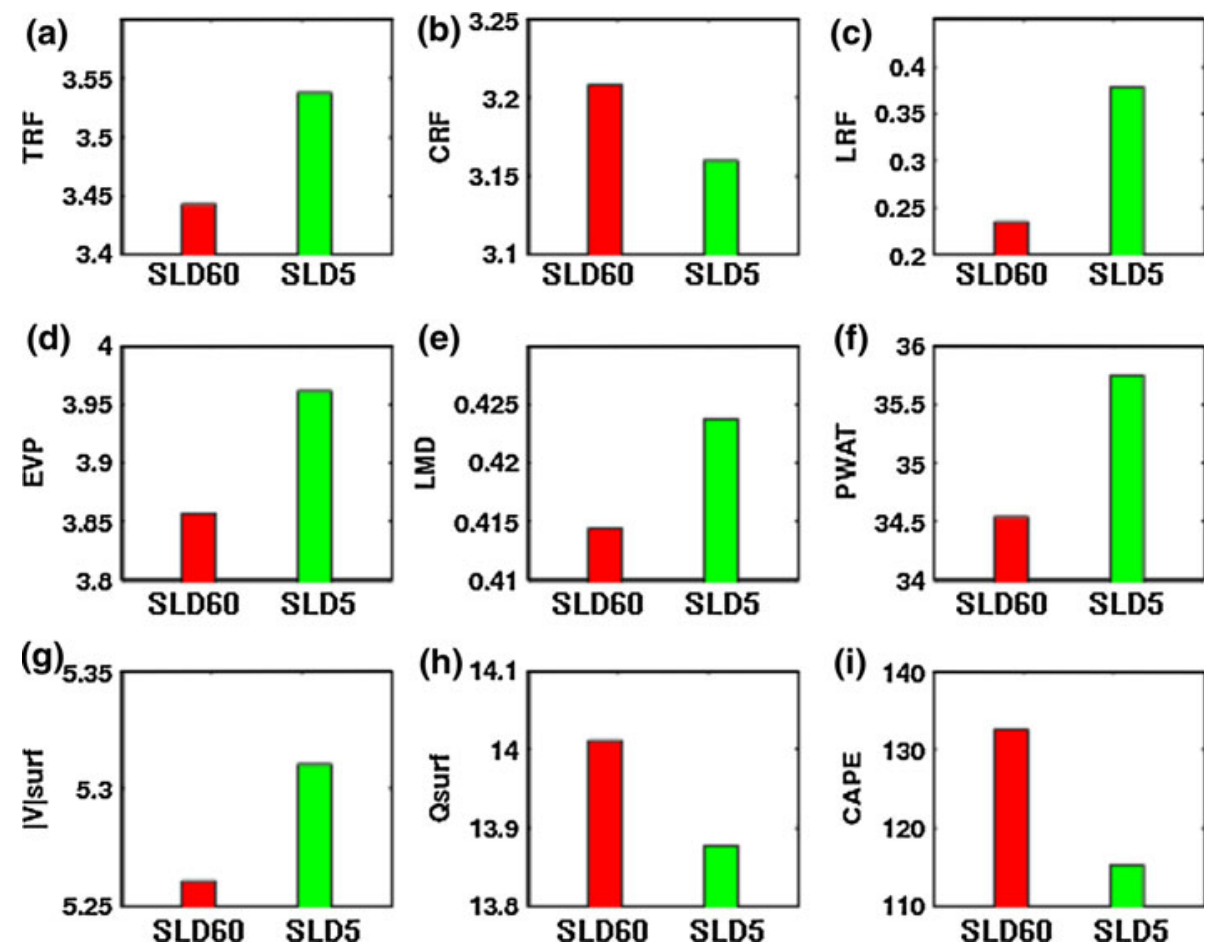
Fig. 2 Vertical profile of the difference of the area averaged, time mean quantities between SLD5 and SLD60, considering only the raining points (TRF $>1 \mathrm{~mm} /$ day) over the tropics. a Relative humidity difference (\%), b specific humidity difference $(\mathrm{g} / \mathrm{kg})$, c atmospheric temperature difference $(\mathrm{K})$. Time mean is calculated by averaging over all the months of 10 years
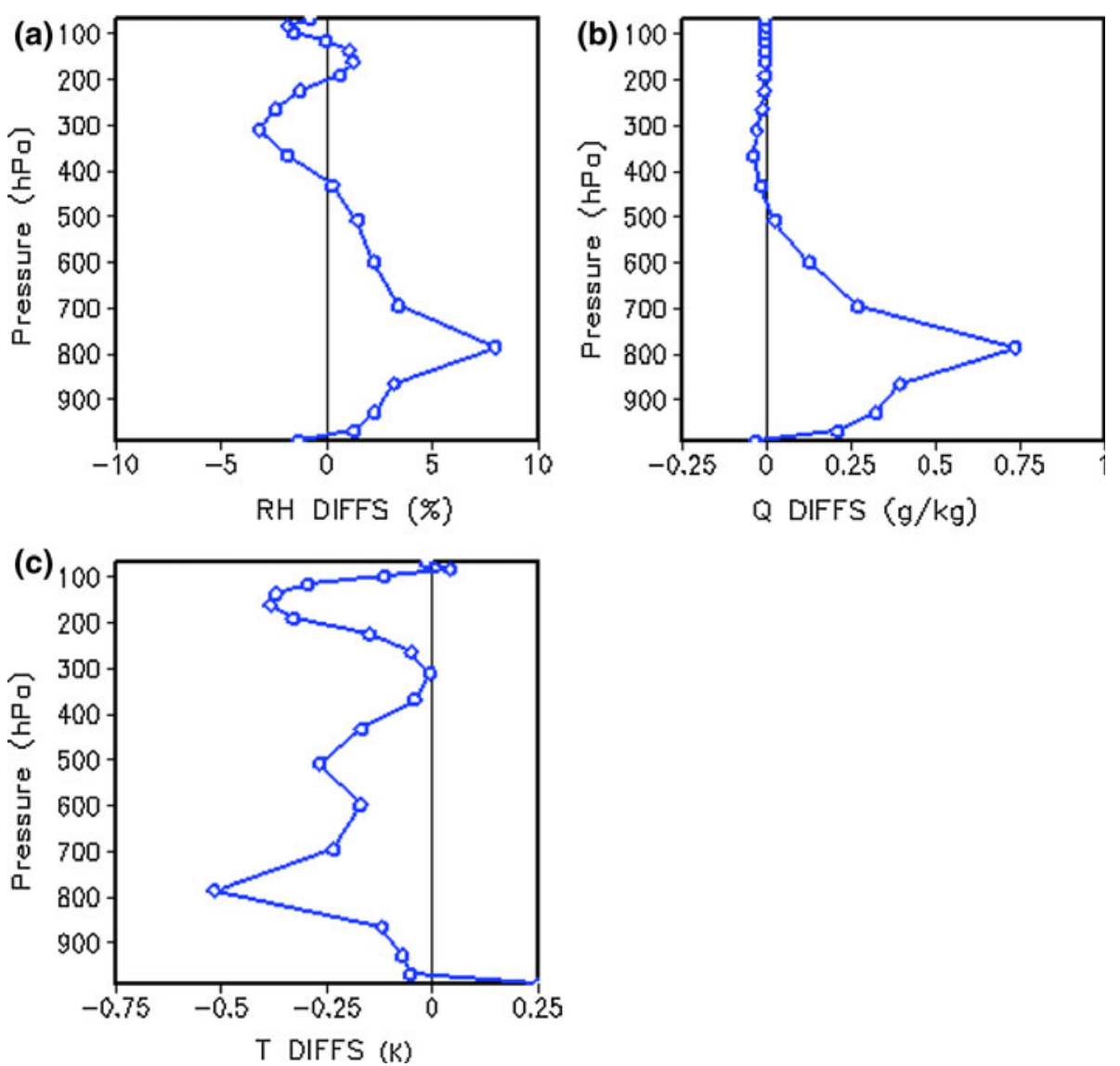

Next, we examine the vertical profiles of the difference of the area averaged, time mean relative humidity (RH), specific humidity $(\mathrm{Q})$, and temperature (T), between SLD5 and SLD60 (using only those grid points where the total rainfall exceeds $1 \mathrm{~mm} /$ day). It is noticed from Fig. 2a that there is an increase in $\mathrm{RH}$ in the lower troposphere (below $500 \mathrm{hPa}$ ). The corresponding differences in the vertical profiles of $\mathrm{Q}$ and $\mathrm{T}$ are shown in Fig. $2 \mathrm{~b}$, and c, respectively. The profile of the difference in $\mathrm{Q}$ closely resembles the profile of the difference in RH, especially in the lower troposphere. In addition, the decrease in $\mathrm{T}$ in the lower troposphere accentuates the increase in RH (see Fig. 2c). In the upper troposphere (above $500 \mathrm{hPa}$ ), the specific humidity with SLD5 is lower, which in turn causes a decrease in RH at those levels. It was noticed (not shown here) that the liquid condensate and ice condensate increase in the upper troposphere with SLD5. The increase of RH in the lower troposphere, and increase of liquid and ice condensate in the upper troposphere, together cause the enhancement of the large-scale rainfall in SLD5.

\subsection{Intensity and frequency of rainfall}

Since the partitioning of total rainfall between the convective and large-scale components can potentially modulate the intensity and frequency of rainfall, we further analyze this aspect using the model output stored at 24-h intervals. Figure 3 shows the frequency distribution of daily rainfall rates (left panel) and the total rainfall falling into each bin (right panel). The figure shows the frequency distribution of TRF for a 365-day period. Figure 3a shows that with a lower time step the frequencies in the dry, moderate, and heavy categories have increased whereas the reverse is true for the light category. Although the rainfall frequency in the dry category is found to increase with a lower time step, the accumulated rainfall for the 365-day period (i.e., product of frequency and the corresponding rainfall intensity) becomes almost equal for the two simulations (SLD60 and SLD5). However, the rainfall accumulated in the moderate and heavy categories are found to be higher with SLD5. Thus, a decrease of time step leads to an increase in the frequencies of moderate, and heavy rainfall categories, which are responsible for the increase in the time mean total rainfall over the tropics.

Figure 4 shows the frequency distribution of the convective and large-scale rainfall. The frequencies of LRF in all rainfall categories are mostly same in both the simulations. However, the accumulated LRF in SLD5 is more for all the rainfall categories except the dry one. This difference in the accumulated LRF, despite of same frequency is 

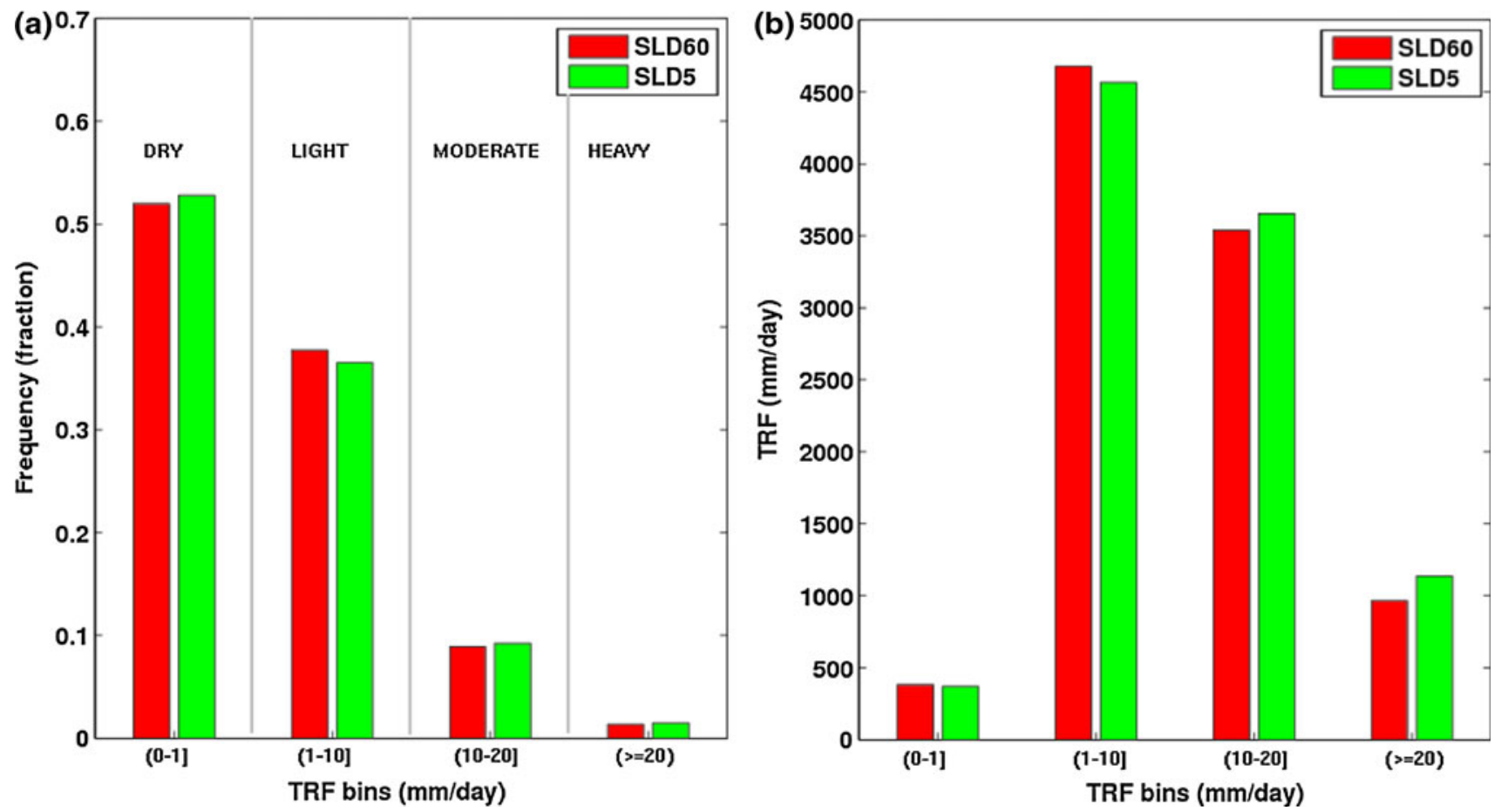

Fig. 3 a Frequency distribution of daily rainfall rates over the tropics (0E-360E and 30S-30 N) for 365 days from SLD60 and SLD5. b Amount of rainfall falling into each bin of rainfall rates

due to the fact that, with SLD5 there is an internal shift towards the upper end within the categorized bin. The aforementioned is apparent in a plot with finer bin size (not shown). With SLD5, frequencies of CRF decrease in dry and heavy categories, but increase in the light category.

In the previous section it was shown that CRF decreases, whereas LRF increases with decrease in time step. Since the accumulated LRF increases in all the rainfall categories excepting the dry category (Fig. 4b2), this causes an increase in the area averaged time mean LRF, whereas the decrease in the accumulated CRF for the heavy category (Fig. $4 \mathrm{~b} 1$ ) results in the decrease of area averaged time mean CRF with SLD5.

\subsection{Spatial distribution of rainfall and its associated state variables}

Here we discuss the impact of time step on the simulation of the spatial distribution of rainfall and its associated state variables. For this, we analyzed the seasonal mean patterns of the variables of interest. The seasonal mean (10 years) rainfall for boreal winter (DJF) and summer (JJA) seasons are compared with observations (CMAP) in Figs. 5 and 6, respectively. In DJF, SLD60 overestimates the rainfall over southern part of Africa, northern part of Australia, the Bay of Bengal, the equatorial western Pacific, and the west coast of South America. On the other hand, SLD60 underestimates rainfall over the equatorial Indian Ocean, western part of the South Pacific, and eastern part of the North America (Fig. 5a, c). These drawbacks partly disappear in SLD5 (refer Fig. 5b-d).

Similarly, in JJA, SLD60 overestimates rainfall over the Saudi Arabia, Indonesia, and north-eastern China, and underestimates over head of the Bay of Bengal, the southern peninsular India, west coast of Malaysia, western region of the northern Pacific, and the equatorial eastern Pacific. SLD5 rectifies these shortcomings to some extent. The pattern correlation of SLD5 with the observed rainfall is better than that of SLD60, in both seasons (see Figs. 5, 6). Thus, in both the seasons there is a considerable improvement in the simulation of spatial distribution of rainfall with finer time step size.

In Fig. 7, we show the contribution of CRF and LRF to the improvement of the simulation of the spatial distribution of rainfall with SLD5. The figure shows that a part of the contribution comes from the change in $\mathrm{CRF}$, and the remaining from the change in LRF. However, the differences in LRF in both the seasons are positive everywhere. It is consistent with the results of Mishra et al. (2008), wherein, using an aquaplanet framework, they reported that LRF monotonically increases with decrease of time step.

Since CRF and LRF are controlled by CAPE and RH, respectively, we examine these two variables. In Fig. 8, we present the difference in CAPE and RH (700 hPa) between SLD5 and SLD60 for both the seasons (left panels for DJF and right panels for JJA). It can be seen that over most of 

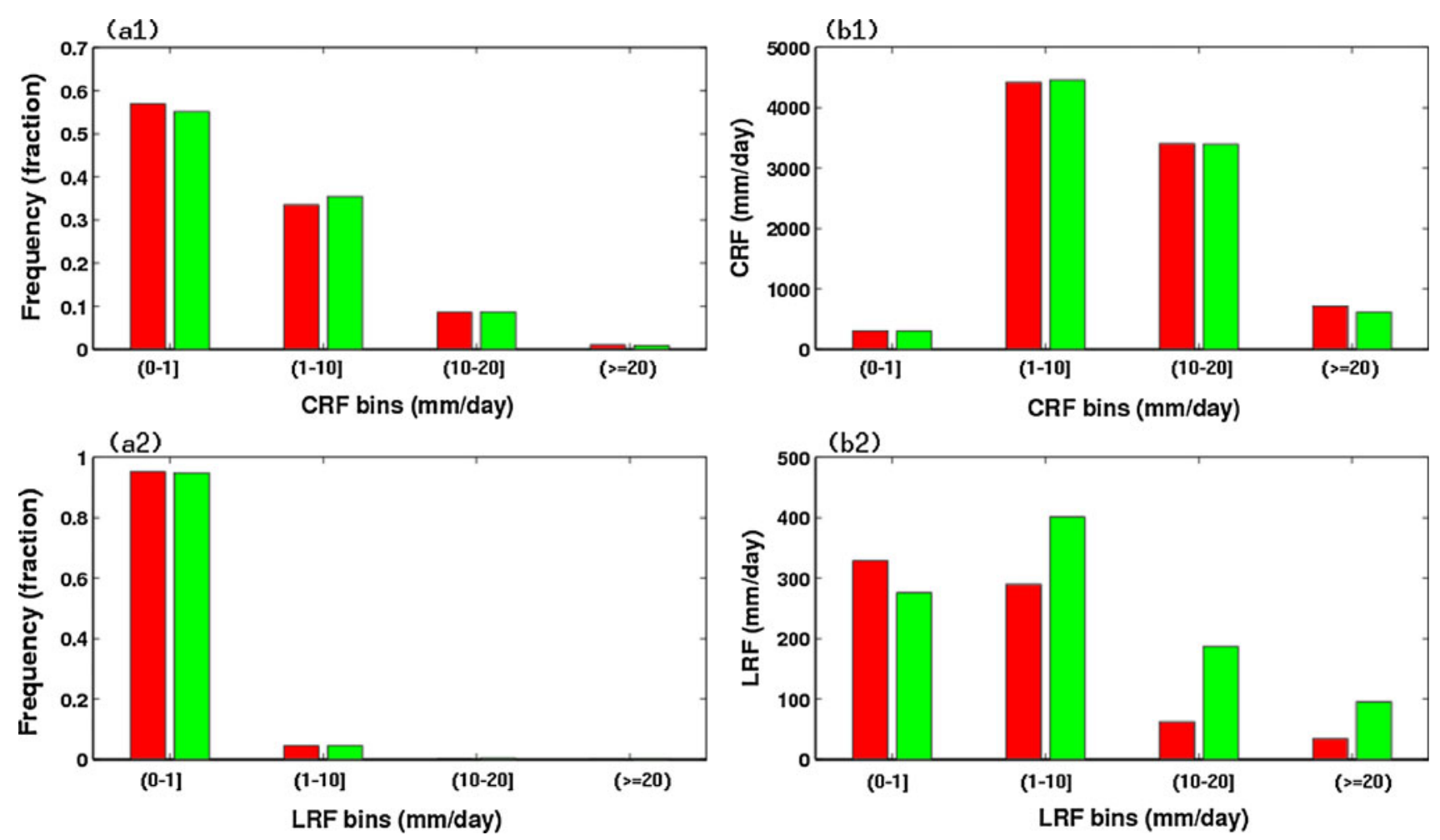

Fig. 4 Same as Fig. 3 but for convective rainfall (top panels) and large-scale rainfall (bottom panels)

Fig. 5 Climatological mean DJF rainfall ( $\mathrm{mm} /$ day) for a SLD60, b SLD5, c CMAP, and d [SLD5-SLD60]. The climatological mean is derived from 10 years (1979-1988) of data. The pattern correlation was computed over $0 \mathrm{E}-360 \mathrm{E}$ and $30 \mathrm{~S}-30 \mathrm{~N}$
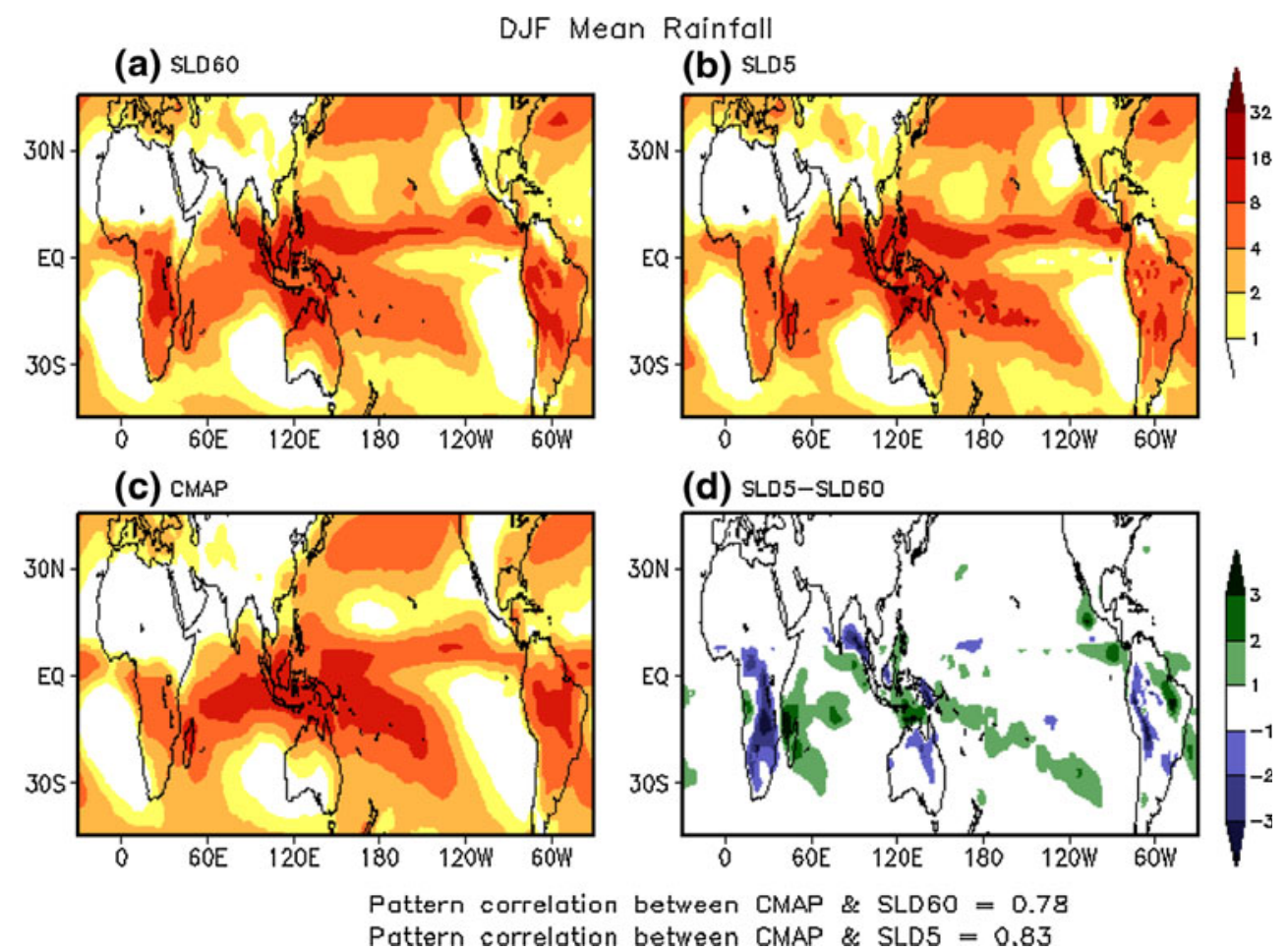

the regions, CAPE is lower and RH is higher with SLD5. Secondly, Fig. 8a, b show that the CAPE is predominantly lower over regions where the CRF is lower and vice versa (refer Fig. 7c, d). Similarly, Fig. 8c, d show a significant enhancement in RH over regions where LRF has increased (refer Fig. 7e, f).

Similarly, the differences in specific humidity and temperature at the same level $(700 \mathrm{hPa})$ are shown in 
Fig. 6 Climatological mean JJA rainfall $(\mathrm{mm} /$ day) for a SLD60, b SLD5, c CMAP, and $\mathbf{d}$ [SLD5-SLD60]. The climatological mean is derived from 10 years (1979-1988) of data. The pattern correlation was computed over $0 \mathrm{E}-360 \mathrm{E}$ and $30 \mathrm{~S}-30 \mathrm{~N}$
Fig. 7 Difference in the climatological mean rainfall ( $\mathrm{mm} /$ day) between SLD5 and SLD60. The left panels are for DJF and the right panels for JJA. a, b Total rainfall, c, $\mathbf{d}$ convective rainfall, and e, f large-scale rainfall. The climatological mean is derived from 10 years (1979-1988) of data (a) $\$ L D 60$

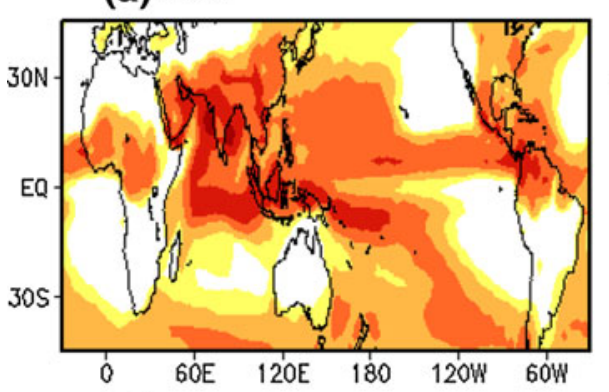

(c) CMAP

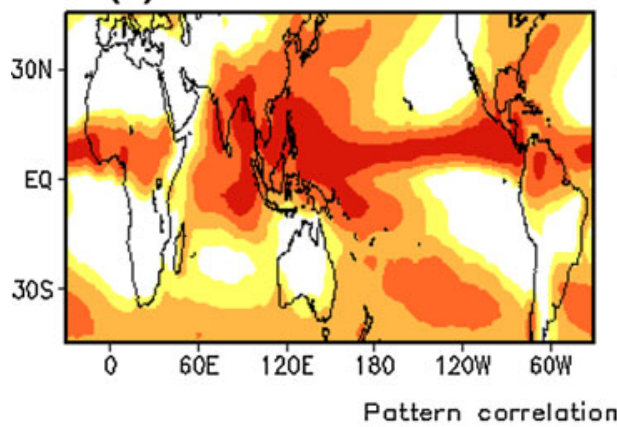

Pattern correlation between CMAP \& SLD5 $=0.72$

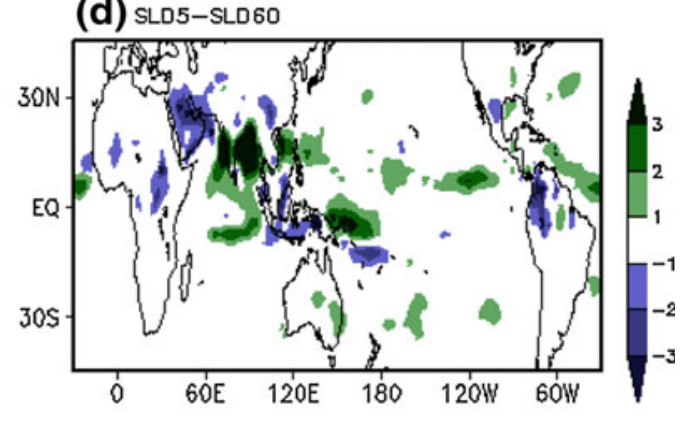

(b) SLD5

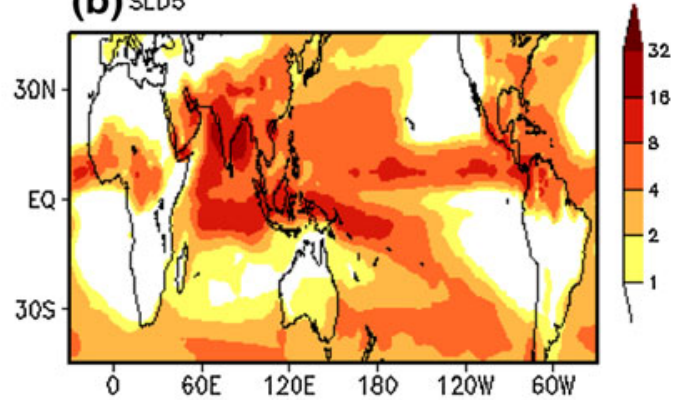

(d) SLD5-SLD60

between CMAP \& SLD5 $=0.72$
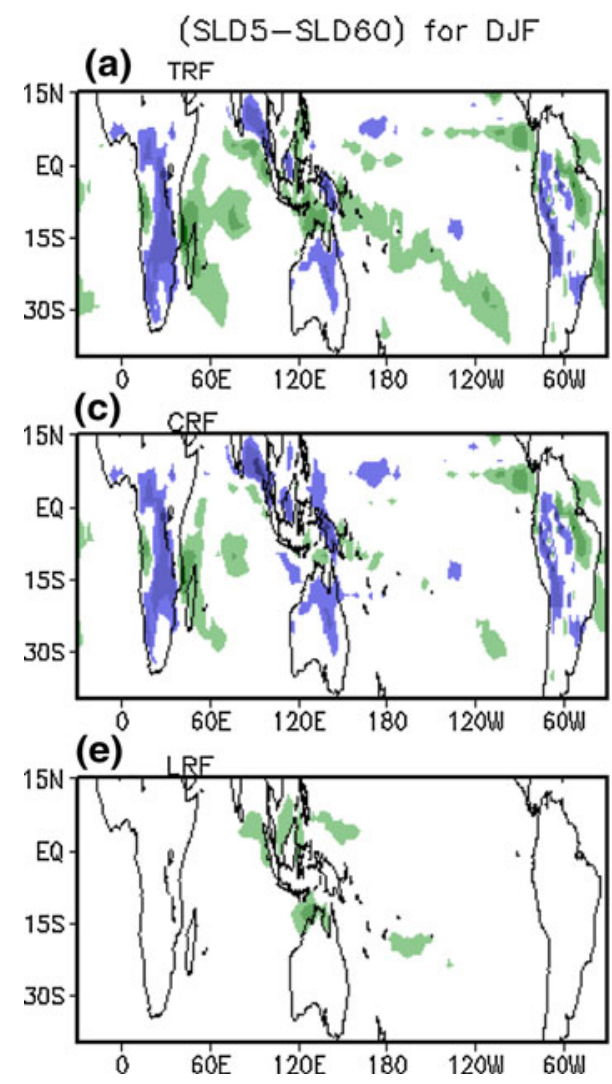

(b) TRF
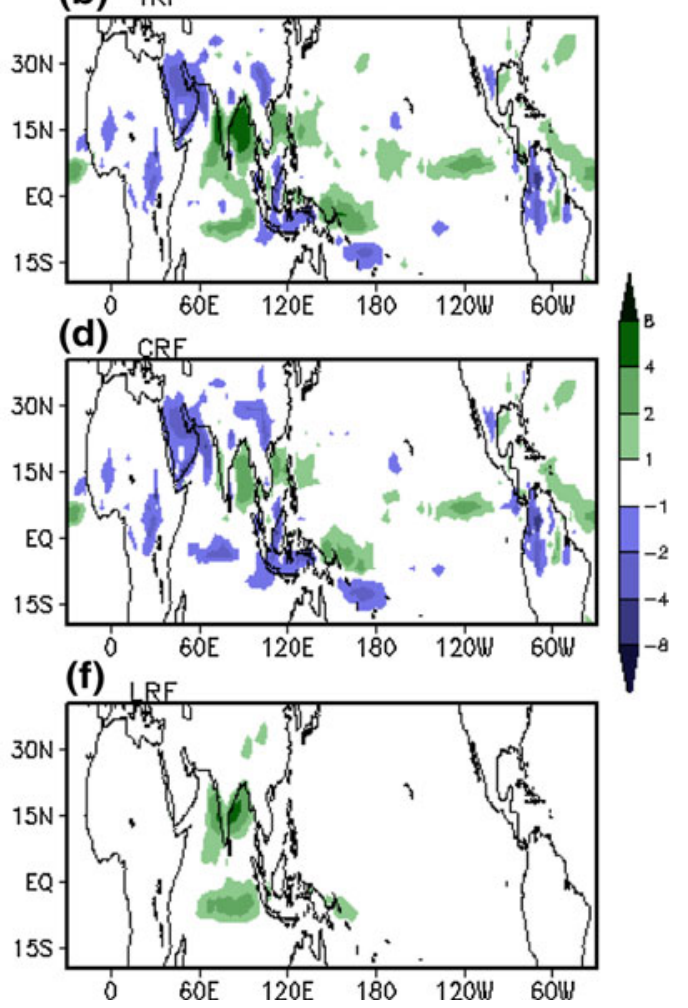

Fig. 9. It shows that in SLD5 the specific humidity is more over the regions where RH was higher. The temperature over some of these locations is lower, which accentuates the increase in RH. Thus, it can be concluded that the enhancement of specific humidity plays a primary role in the enhancement of RH with SLD5. From Fig. 10, 
Fig. 8 Difference in the climatological mean quantities between SLD5 and SLD60. The left panels are for DJF and the right panels for JJA.

a, b Convective available potential energy $(\mathrm{J} / \mathrm{kg})$,

c, $\mathbf{d}$ relative humidity at $700 \mathrm{hPa}(\%)$. The

climatological mean is derived from 10 years $(1979-1988)$ of data

Fig. 9 Difference in the climatological mean quantities between SLD5 and SLD60. The left panels are for DJF and the right panels for JJA.

a, b Specific humidity at $700 \mathrm{hPa}(\mathrm{g} / \mathrm{kg}), \mathbf{c}, \mathbf{d}$ air temperature at $700 \mathrm{hPa}(\mathrm{K})$. The climatological mean is derived from 10 years (1979-1988) of data
(SLD5-SLD60) for DJF
(a) CAPE

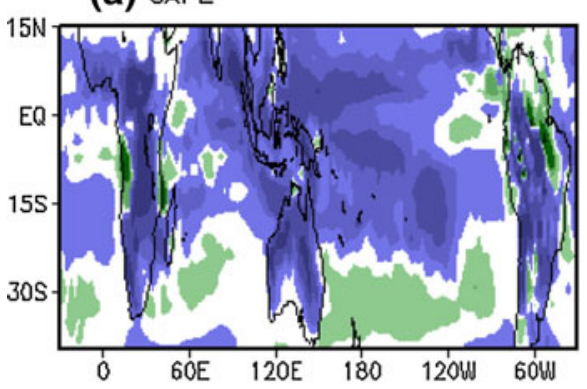

(c) $\mathrm{RH}(700 \mathrm{hPa})$

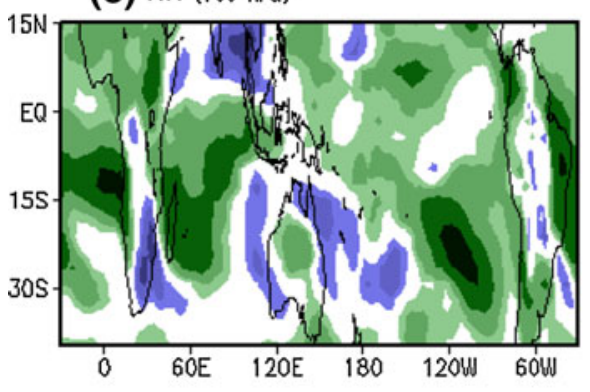

(SLD5-SLD60) for DJF

(a) $Q$

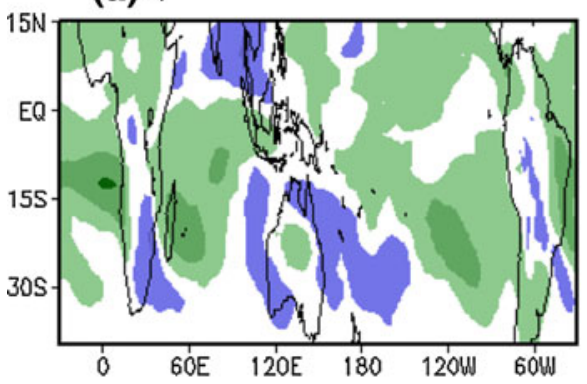

(c) $\mathrm{T}$

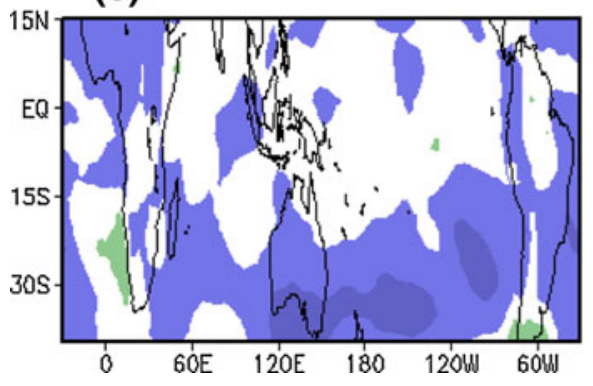

(SLD5-SLD60) for JJA
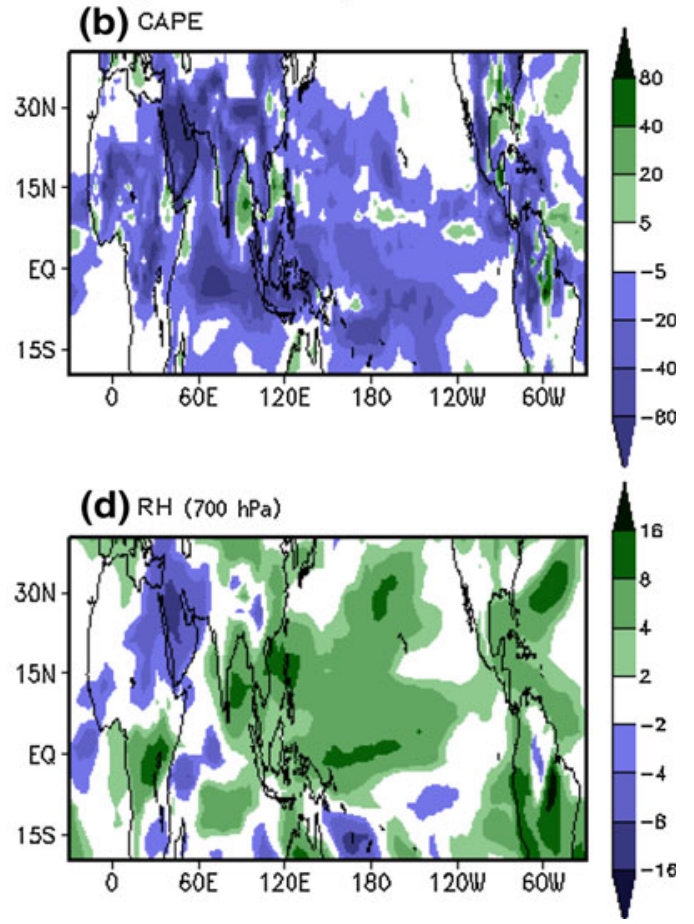

(b) 0

(SLD5-SLD60) for JJA

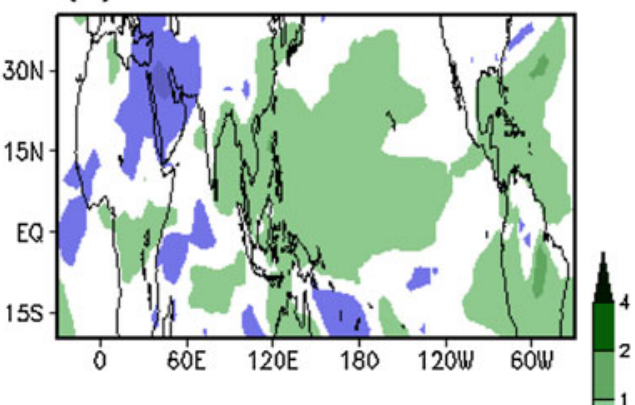

(d) $\mathrm{T}$

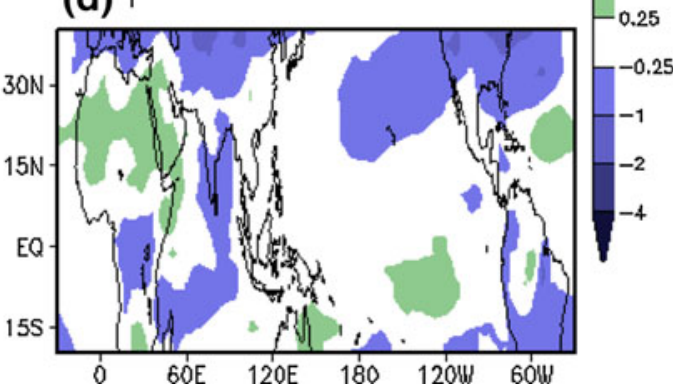

we see that the source of enhancement in the specific humidity at those locations is the large-scale moisture convergence, not the local surface evaporation, in both seasons. In Fig. 11, the wind at the 1st model level is presented. The vector shows the wind direction, and the background shading indicates its magnitude. There appears a resemblance between the difference in the wind strength at the 1st model level (Fig. 11c1, c2) and the difference in evaporation (see Fig. 10a, b). We analyzed the $850 \mathrm{hPa}$ wind pattern and found a largely similar pattern as shown in Fig. 11. During DJF, in the lower troposphere, the cross-equatorial easterlies over the Indian longitudes are stronger, which appears to bring more moisture into the southern Indian Ocean convergence zone 
Fig. 10 Difference in the climatological mean quantities between SLD5 and SLD60. The left panels are for DJF and the right panels for JJA.

a, b Surface evaporation (mm/day), c, d large-scale moisture convergence ( $\mathrm{mm} /$ day). The climatological mean is derived from 10 years (1979-1988) of data

Fig. 11 Climatological mean wind at the 1st model level $(\mathrm{m} / \mathrm{s})$. Left panels for DJF and right panels for JJA.

a1, a2 SLD60, b1, b2 SLD5, c1, c2 [SLD5-SLD60]. The climatological mean is derived from 10 years (1979-1988) of data
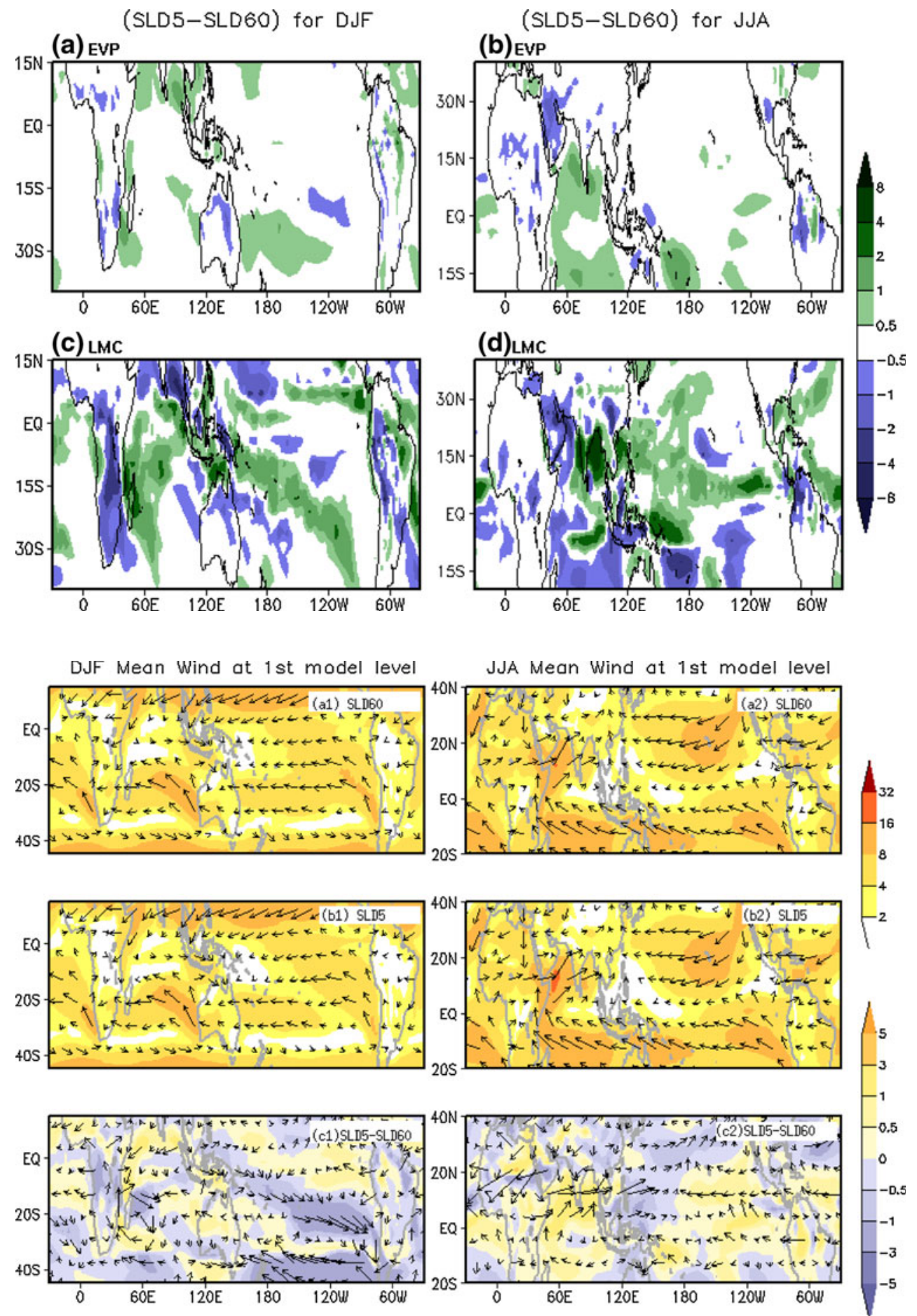

from the western Pacific. Similarly, the enhancement in the moisture convergence in the South Pacific, is due to the fact that, over the south of the equatorial Pacific, the southward moving wind has a higher meridional component, which brings more moisture from the western pacific to the south Pacific, and in turn enhances the moisture convergence there. During JJA, the cross-equatorial easterlies over 60E-120E increases with SLD5, this brings more moisture from the southern Indian Ocean and South Pacific Ocean, and enhances the moisture convergence over India and its surrounding ocean. In JJA, the Somali jet is found to be stronger and extends farther to the east with SLD5, thus bringing more moisture into the western Pacific from the southern Indian Ocean and the south Pacific Ocean, and thus enhancing the moisture convergence over the region. 


\subsection{Equatorial waves}

Since the rainfall partitioning is also expected to alter the vertical structure of latent heat release, thereby affecting wave activity in the tropics, we further analyze 10 years of daily OLR data from the model runs and observations to investigate the influence of time step on the simulation of equatorial waves.

The equatorial wave propagation characteristics of the simulations and observations are compared via wavenumber-frequency diagrams following the spectral analysis methodology of Wheeler and Kiladis (1999, hereafter WK99). Figure 12 shows the symmetric component (as in WK99) from NOAA observations (OBS) and simulations (SLD60, and SLD5). Similarly the antisymmetric component (as in WK99) for different cases is shown in Fig. 13. The regions of wavenumber-frequency space defining the Kelvin, $n=1$ equatorial Rossby (ER), mixed Rossbygravity (MRG), $n=0$ eastward inertio-gravity (EIG), $n=1$ westward inertio-gravity ( $n=1 \mathrm{WIG}$ ), and Madden Julian Oscillation (MJO) modes are similar to WK99. The conventional dispersion curves of shallow water modes for equivalent depths of 12,25 , and $50 \mathrm{~m}$ are shown in the figures.
At frequencies greater than 0.2 cycles per day (cpd), there appears to be an increase in speed of Kelvin waves in SLD60 (see Fig. 12b), but the reverse is true in observations (see Fig. 12a). This is a typical shortcoming of many GCMs (Slingo et al. 1996). This drawback is reduced to some extent in SLD5 (see Fig. 12c).

In SLD60, the Kelvin waves have most of their variance centered on an equivalent depth of approximately $50 \mathrm{~m}$ at lower wavenumbers $(<5)$, corresponding to a speed of around $22.1 \mathrm{~m} / \mathrm{s}$. At higher wavenumbers $(>6)$, the variance is centered on higher equivalent depths. In SLD5, at lower wavenumbers $(<5)$ the variance is centered on $50 \mathrm{~m}$ equivalent depth, but at higher wavenumbers $(>6)$ most of the variance is at lesser equivalent depths. Hence, there is an indication of slowing down of Kelvin waves with a decrease in time step. Secondly, there is a decrease in power at high frequencies $(>0.20 \mathrm{cpd})$ and higher wavenumbers ( $>4)$. MJO is known to be one of the most important eastward propagating modes, with period $30-70$ days and wavenumbers $1-5$. The symmetric component of the MJO is seen in Fig. 12. Both the simulations show some variance within these bands, though weaker than observations. The symmetric component of the westward propagating disturbances in the wavenumber (a) OBS.

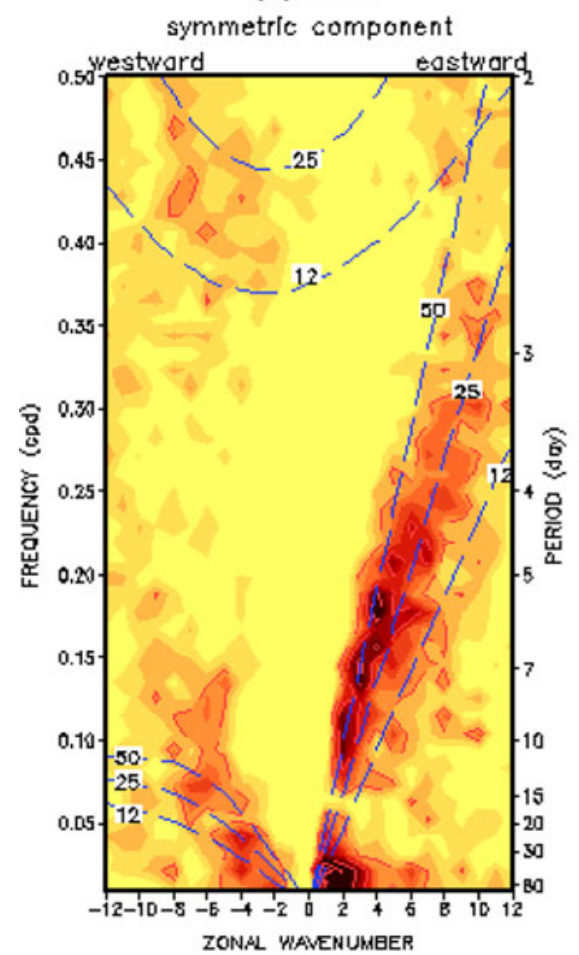

(b) SLDG0 symmetrls component

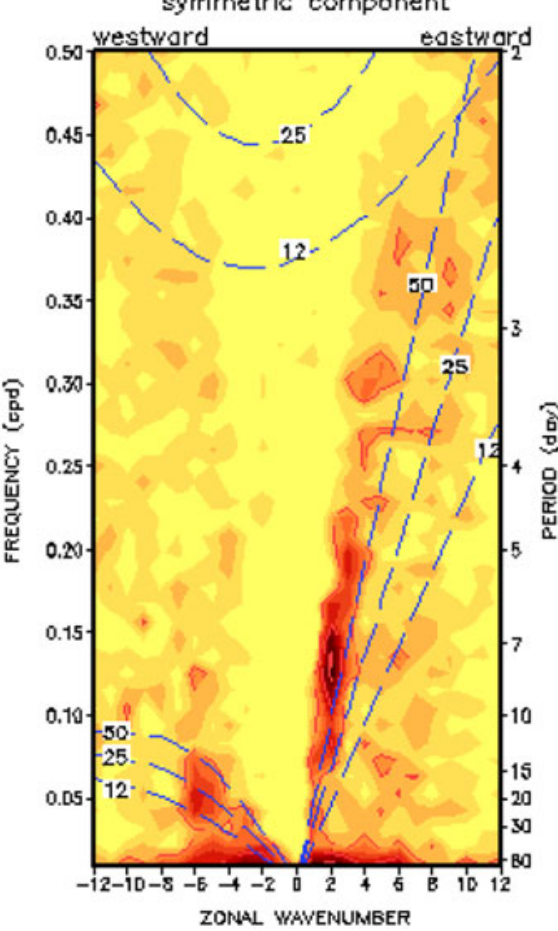

(c) SLD5

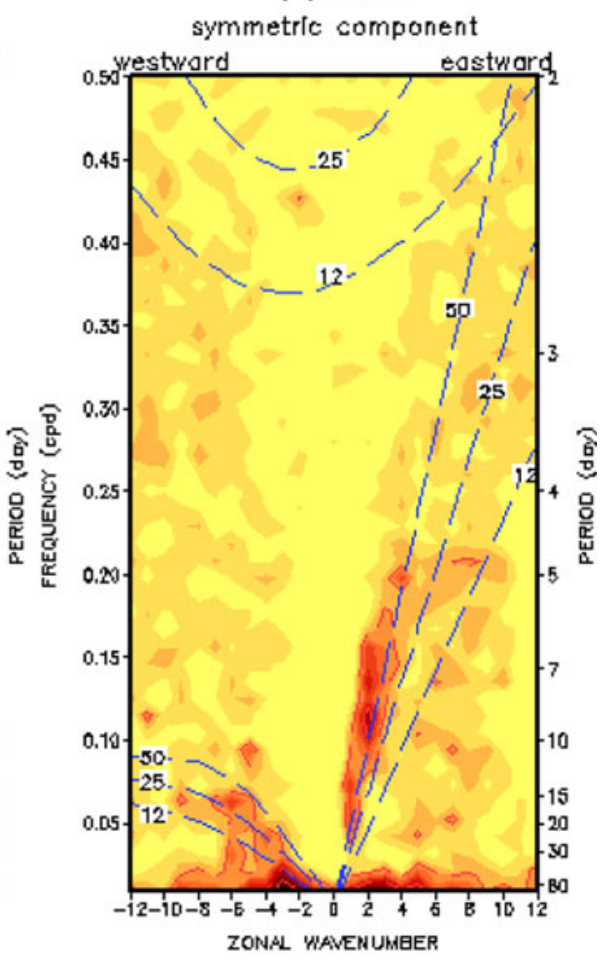

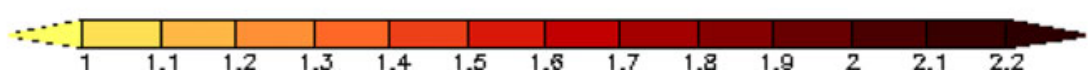

Fig. 12 The symmetric component of the wavenumber-frequency distribution of OLR averaged between $15 \mathrm{~S}$ and $15 \mathrm{~N}$ is shown for a OBS (NOAA), b SLD60, and c SLD5 
(a) OBS. antlsymmetric component

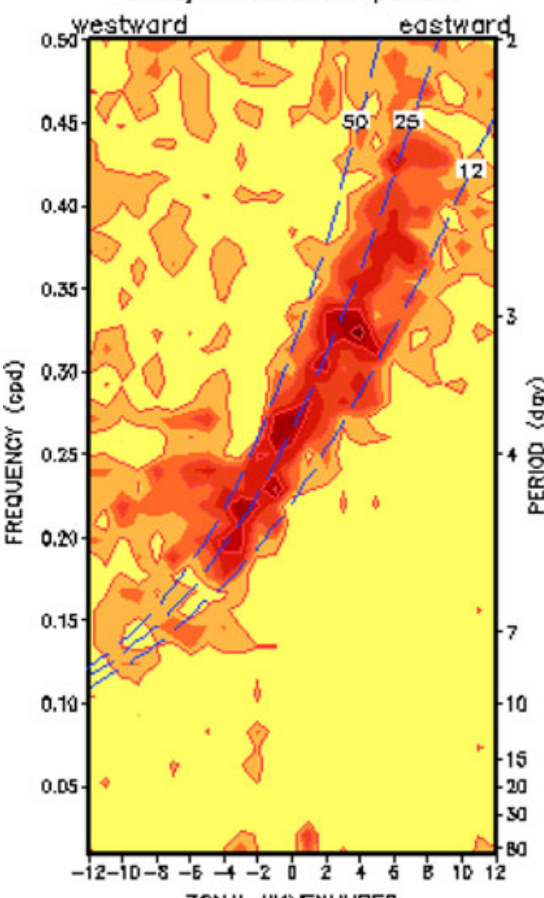

ZONAL WAVENUWIEER (b) SLD60 antrsymmetrls component

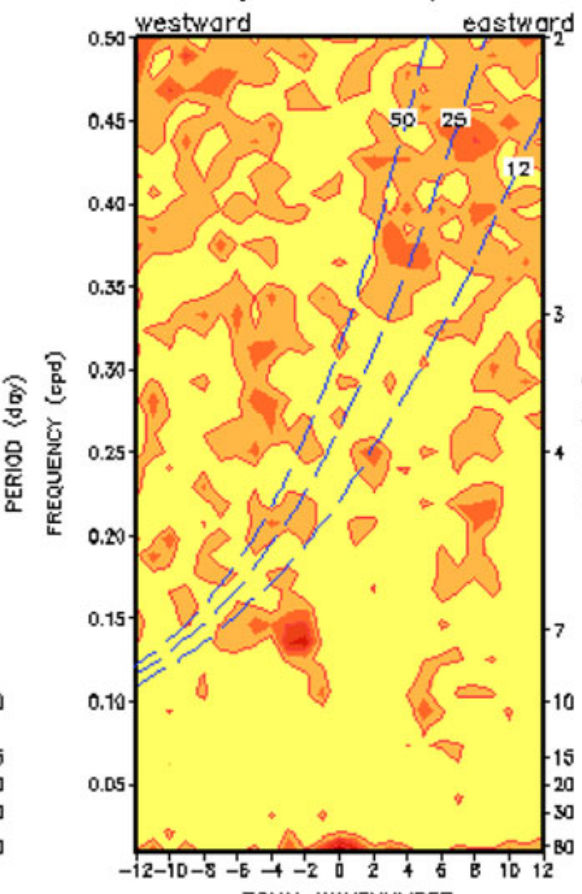

(c) SLD5

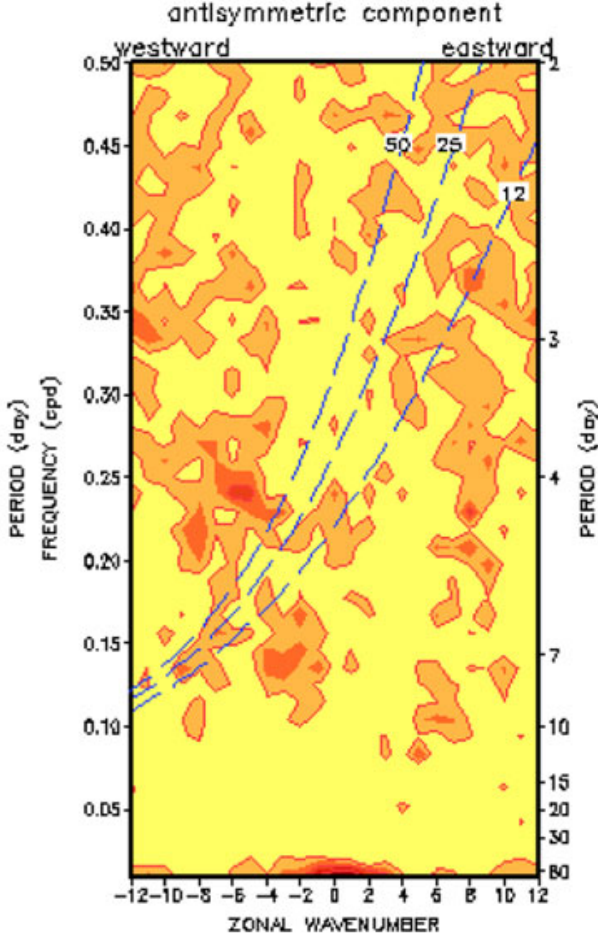

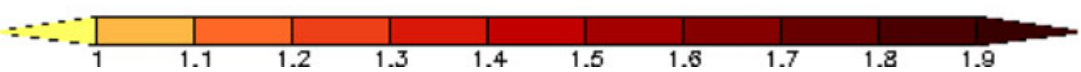

Fig. 13 The antisymmetric component of the wavenumber-frequency distribution of OLR averaged between $15 \mathrm{~S}$ and $15 \mathrm{~N}$ is shown for a OBS (NOAA), b SLD60, and c SLD5

range of $1-10$ and period from 10 to 20 days is the $n=1$ ER. SLD60 simulates $n=1$ ER waves to a satisfactory level, except that the power is lacking at higher wavenumbers ( $>6$ ), which is worse in SLD5. The $n=1 \mathrm{WIG}$ is another symmetric component of the westward propagating waves with less than 2.5 days time scale. In this regime, the variance is underestimated in both the simulations. Figure 13 shows that, in $n=0$ EIG regime, SLD5 has less power than SLD60 in the faster modes but more power in slower modes. The power in MRG waves in SLD5 is higher than that in SLD60.

Since vertical structure of the moist heating is crucial in determining the speed of the eastward propagations, we show the same for both the simulations in Fig. 14a, for the equatorial region $(15 \mathrm{~S}-15 \mathrm{~N})$. Comparison of SLD60 and SLD5 indicates that in the lower troposphere, SLD5 has a greater heating rate than SLD60. Hence, comparatively, the bottom-heaviness in the heating profile is greater in SLD5 than that in SLD60. In order to investigate the reason for the difference in the moist heating profiles, the vertical distributions of the convective and large-scale precipitation rates are plotted in Fig. 14b, c, respectively. Decrease of time step leads to an increase in convective precipitation $(\mathrm{CP})$ in the lower troposphere accompanied with a decrease of the same in upper troposphere. On the other hand, large- scale precipitation (LSP) remains almost same in the lower troposphere, but increases in the upper troposphere. The changes in the magnitude of CP and LSP in the upper troposphere are of the same order and hence compensate each other. Whereas, in the lower troposphere, the increase in $\mathrm{CP}$ makes the vertical heating profile more bottomheavy and is perhaps responsible for lower phase speed of the Kelvin waves.

\subsection{Consistency of the effects}

In order to verify if there is a systematic impact of time step on the simulated tropical climate, we carried out an additional 10-year long simulation with 20 min time step size (referred to as SLD20) similar to SLD60 and SLD5. Figure 15 shows the statistics of some important variables from the three simulations. The variables shown are: total surface reaching rainfall (TRF in $\mathrm{mm} /$ day), surface evaporation (EVP in $\mathrm{mm} /$ day), precipitable water (PWAT in $\mathrm{kg} / \mathrm{m}^{2}$ ), lowest model level wind strength (IVlsurf in $\mathrm{m} / \mathrm{s}$ ), vertically-integrated high cloud (CLDHGH in fraction), vertically integrated mid-level cloud (CLDMED in fraction), vertically integrated low cloud (CLDLOW in fraction), longwave cloud forcing ( $\mathrm{LWCF}$ in $\mathrm{W} / \mathrm{m}^{2}$ ), and shortwave cloud forcing $\left(\mathrm{SWCF}\right.$ in $\left.\mathrm{W} / \mathrm{m}^{2}\right)$. These are time 
Fig. 14 Vertical distribution of a moist heating, b convective precipitation rate, and $\mathbf{c}$ largescale precipitation rate in the equatorial belt $(0 \mathrm{E}-360 \mathrm{E}$ and $15 \mathrm{~S}-15 \mathrm{~N})$ from SLD60 and SLD5
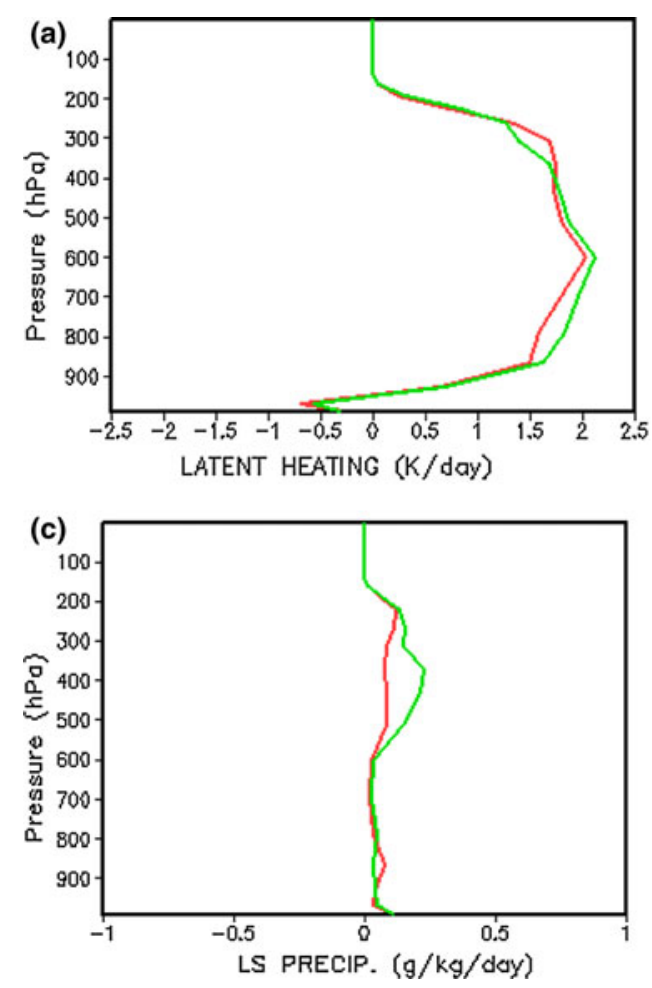
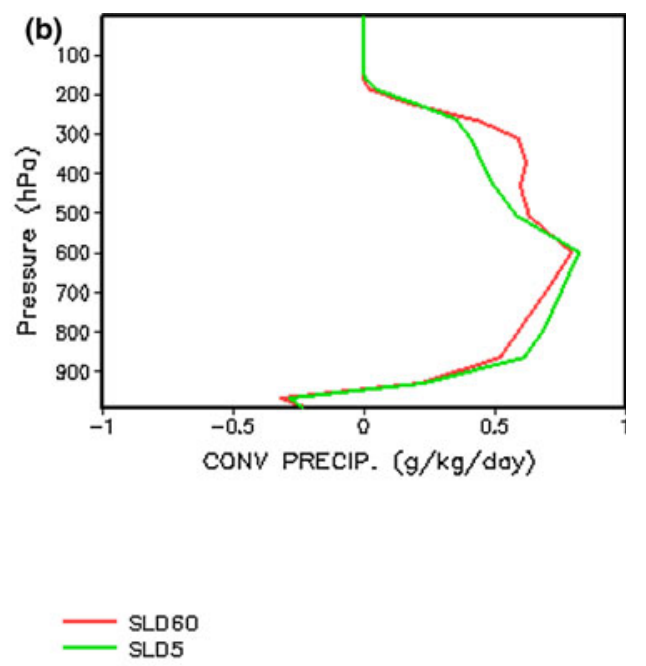

mean values over all months for the 10 -year simulations, and area averaged over the tropics $(0 \mathrm{E}-360 \mathrm{E}$ and $30 \mathrm{~S}-$ $30 \mathrm{~N})$. It can be clearly seen from Fig. 15, that there is a systematic change in the variables with change in time step size. With decrease of time step, there is an increase in wind strength at the lowest model level, which enhances the surface evaporation, and subsequently precipitable water and eventually the rainfall. The low and mid-level clouds increase due to enhancement of moisture and relative humidity in the lower and mid-troposphere (also refer Fig. 2). Whereas, in the upper troposphere, the moisture and relative humidity decrease and hence the high clouds show the reverse trend. The increase in low and mid-level clouds results in an increase in both longwave cloud forcing as well as shortwave cloud forcing. The order of change in SWCF is much larger than that in LWCF, and hence leads to a reduction in atmospheric temperature with decrease of time step. This phenomena is similar to the one discussed in Sect. 3.1, however the progressive change across 3 time steps confirms the consistency of the effects. Furthermore, we carried out an additional set of simulations in aqua-planet framework with 4 different time steps i.e., $60 \mathrm{~min}$ (SLD60), $30 \mathrm{~min}$ (SLD30), $20 \mathrm{~min}$ (SLD20), and $5 \mathrm{~min}$ (SLD5) by using the Neale and Hoskins protocol SST discussed in Sect. 2.2. The motivation of using an aqua-planet is to make sure that the results are consistent across model configurations. Figure 16 shows the same set of variables shown in Fig. 15 but from aqua-planet simulations. The changes in the variables are similar to that noticed in Fig. 15, i.e., all the variables except CLDHGH show an increase with decrease of time step. Hence, the effects of time step are found to be consistent and robust across different modeling frameworks.

\section{Discussion and conclusions}

In this study, the effects of model time step on the simulation of tropical climate have been demonstrated using the NCAR-CAM3 GCM. It has been found that with a lower time step there is an increase in total rainfall over the tropics. Analysis of the individual rainfall components reveals that, with a lower time step, while there is a decrease in the convective component of rainfall, there is an even larger increase in the stratiform component, thus leading to an overall increase in the total rainfall. When using a smaller time step, the wind speed at the lower model levels becomes stronger, thus causing a higher surface evaporation. This leads to an increase in atmospheric water vapor, and a higher relative humidity. Higher relative humidity in the atmosphere, in turn, leads to more stratiform rainfall. The intensity and frequency of simulated rainfall are found to depend on the time step size used for numerical integrations. Reduction of time step increases the frequency of moderate and intense rainfall categories, and decreases that of the light rainfall category. In regard to the spatial distribution of rainfall, a lower time step is found to produce more realistic simulation of the rainfall 
Fig. 15 Area averaged $(0 \mathrm{E}-360 \mathrm{E}$ and $30 \mathrm{~S}-30 \mathrm{~N})$, time mean (all months of 10 years) quantities for SLD60, SLD20 and SLD5. a Total rainfall (mm/day), b surface evaporation ( $\mathrm{mm} /$ day), c precipitable water $\left(\mathrm{kg} / \mathrm{m}^{2}\right)$, d magnitude of wind at the 1 st model level $(\mathrm{m} / \mathrm{s})$, e vertically integrated high cloud (fraction), f vertically integrated mid-level cloud (fraction), $\mathbf{g}$ vertically integrated low level cloud (fraction), $\mathbf{h}$ longwave cloud forcing $\left(\mathrm{W} / \mathrm{m}^{2}\right)$, and $\mathbf{i}$ shortwave cloud forcing $\left(\mathrm{W} / \mathrm{m}^{2}\right)$
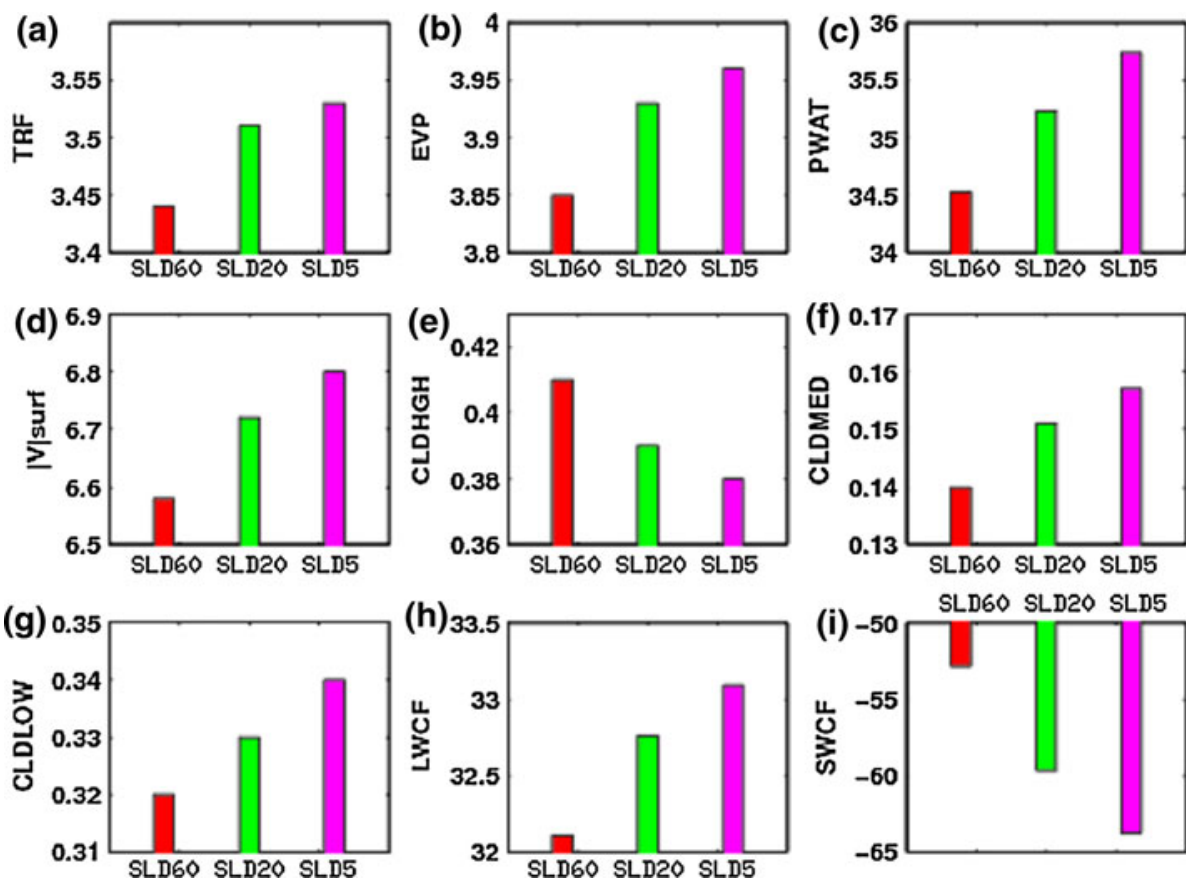

Fig. 16 Area averaged $(0 \mathrm{E}-360 \mathrm{E}$ and $30 \mathrm{~S}-30 \mathrm{~N})$, time mean (all months of 10 years) quantities for SLD60, SLD30, SLD20 and SLD5 from aquaplanet simulations. a Total rainfall $(\mathrm{mm} /$ day $)$, b surface evaporation ( $\mathrm{mm} /$ day), c precipitable water $\left(\mathrm{kg} / \mathrm{m}^{2}\right)$, d magnitude of wind at the $1 \mathrm{st}$ model level $(\mathrm{m} / \mathrm{s})$, e vertically integrated high cloud (fraction), f vertically integrated mid-level cloud (fraction), $\mathbf{g}$ vertically integrated low level cloud (fraction), $\mathbf{h}$ longwave cloud forcing $\left(\mathrm{W} / \mathrm{m}^{2}\right)$, and $\mathbf{i}$ shortwave cloud forcing $\left(\mathrm{W} / \mathrm{m}^{2}\right)$
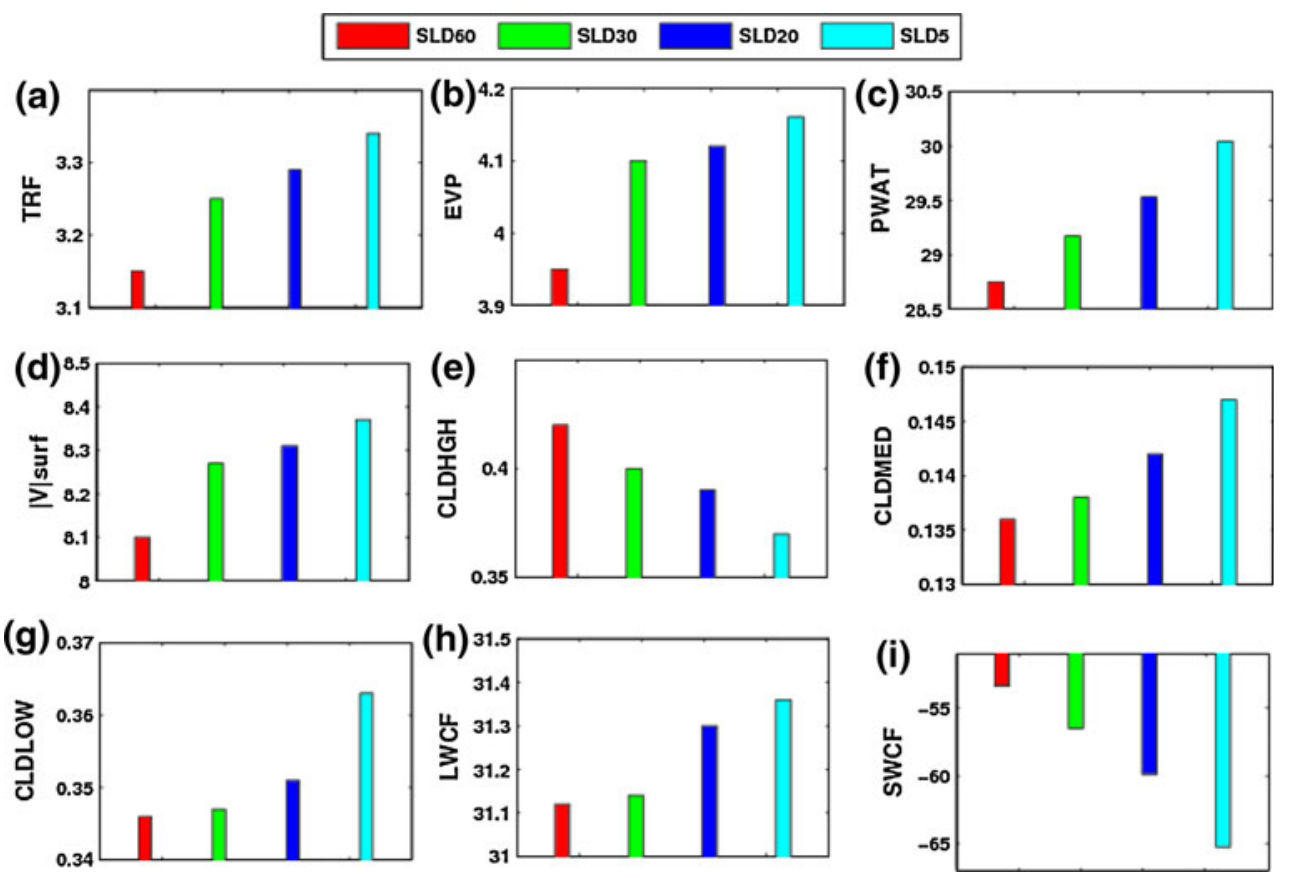

pattern, and thus leading to a higher spatial correlation with observations. Analysis of the behavior of simulated equatorial waves shows that the Kelvin waves become slower with a reduction in time step size. Decrease of time step leads to an increase in convective precipitation in the lower troposphere accompanied with a decrease of the same in the upper troposphere. On the other hand, large scale precipitation remains almost the same in the lower troposphere, but increases in the upper troposphere. The changes in the magnitude of convective and large-scale precipitations in the upper troposphere are of the same order and hence compensate each other. Whereas, in the lower troposphere increase in convective precipitation leads to a vertical heating profile that is more bottom-heavy and is perhaps responsible for slowing down the Kelvin waves.

Lastly, in order to validate the consistency of the effects of change in time step size on the simulation of tropical climate, additional numerical experiments were conducted with a $20 \mathrm{~min}$ time step size in the real-planet 
configuration, and with four different time steps $(60,30$, 20 , and $5 \mathrm{~min}$ ) in the aqua-planet configuration. Analysis of a variety of important meteorological variables shows a consistent and systematic change associated with time step size, which is robust across different modeling frameworks, thus adding credibility to the results presented.

In conclusion, it is realized that the simulated tropical climate is sensitive to the time step size used for numerical integrations. One of the primary objectives of the community working on dynamical cores is to develop computationally more efficient dycores by lengthening the maximum permissible time step. A basic underlying assumption in the midst of this effort is that the time step does not have a significant bearing on the quality of simulations, as long as it satisfies the numerical stability criteria. On the other hand, rapid growth of computational power could enable the user to use a finer time step. However, there is no such consensus on how to decide the time step size for a simulation. It is noticed in the literature that the time step is a loosely constrained parameter, which is used in a wide range based on the interest of the user and many a times arbitrarily.

This paper highlights the importance of time step and suggests the community to consider this efficiency versus accuracy issue while selecting a time step for a numerical integration. However, at this point an open question is: what is the "best" time step size for any given simulation? This needs to be investigated and opens the door for future research.

Acknowledgments SKM thanks Ram Nair, Joe Tribbia, Brian Mapes, Kevin Raeder, and J. Srinivasan for valuable interactions on related topics. SS thanks David Neelin for numerous discussions on subjects related to tropical climate. We thank two anonymous reviewers and Editor (Edwin Schneider) for their constructive comments and guidance, which has helped improve the work substantially.

Open Access This article is distributed under the terms of the Creative Commons Attribution Noncommercial License which permits any noncommercial use, distribution, and reproduction in any medium, provided the original author(s) and source are credited.

\section{References}

Beljaars ACM (1991) Numerical schemes for parametrizations. In: Proceedings on numerical methods in atmospheric models. ECMWF, UK, vol 2, pp 1-42

Collins WD et al (2004) Description of the NCAR community atmosphere model (CAM3). Tech Rep NCAR/TN-464+STR. National Center for Atmospheric Research, Boulder, CO, $226 \mathrm{p}$

Courant R, Friedrichs K, Lewy H (1967) On the partial difference equations of mathematical physics. IBM J 11:215-234

Girard C, Delage Y (1990) Stable schemes for nonlinear vertical diffusion in atmospheric circulation models. Mon Wea Rev 118:737-745
Hack JJ (1994) Parameterization of moist convection in the National Center for Atmospheric Research Community Climate Model (CCM2). J Geophys Res 99:(D3), 5551-5568. doi: 10.1029/93JD03478

Hack JJ et al (2006) Simulation of the global hydrological cycle in the CCSM Community Atmosphere Model Version 3 (CAM3): mean features. J Clim 19:2199-2221

Hurrell JW, Hack JJ, Phillips AS, Caron J, Yin J (2006) The dynamical simulation of the community atmosphere model version 3 (CAM3). J Clim 19:2162-2183

Jakob C, Pier Siebesma A (2003) A new subcloud model for massflux convection schemes: influence on triggering, updraft properties, and model climate. Mon Wea Rev 131:2765-2778

Liebmann B, Smith CA (1996) Description of a complete (interpolated) outgoing longwave radiation datasets. Bull Amer Meteor Soc 77:1275-1277

Locatelli JD, Hobbs PV (1974) Fall speeds and masses of solid precipitation particles. J Geophys Res 79(15):2185-2197. doi: 10.1029/JC079i015p02185

McFarlane NA (1987) The effect of orographically excited gravity wave drag on the general circulation of the lower stratosphere and troposphere. J Atmos Sci 44:1775-1800

Mishra SK, Srinivasan J (2010) Sensitivity of the simulated precipitation to changes in convective relaxation time scale. Ann Geophys (in press)

Mishra SK, Srinivasan J, Nanjundiah RS (2008) The impact of the time step on the intensity of ITCZ in an aqua-planet GCM. Mon Wea Rev 136:4077-4091

Neale RB, Hoskins BJ (2000) A standard test for AGCMs including their physical parametrizations. I: The proposal. Atmos Sci Lett 1:101-107

Rasch PJ, Kristjansson JE (1998) A comparison of the CCM3 model climate using diagnosed and predicted condensate parameterizations. J Clim 11:1587-1613

Rasch PJ et al (2006) A characterization of tropical transient activity in the CAM3 atmospheric hydrological cycle. J Clim 19:2222-2242

Rayner NA et al (2003) Globally complete analyses of sea surface temperature, sea ice and night marine air temperature. J Geophys Res 108(D14):4407. doi:10.1029/2002JD002670

Reynolds RW, Rayner NA, Smith TM, Stokes Wang W (2002) An improved in situ and satellite SST analysis for climate. J Clim 15:1609-1625

Sahany S, Nanjundiah RS (2008) Impact of convective downdrafts on model simulations: Results from aqua-planet integrations. Ann Geophys 26:1877-1887

Slingo JM et al (1996) Intraseasonal oscillation in 15 atmospheric general circulation models: Results from an AMIP diagnostic sub-project. Clim Dyn 12:422-479

Sundqvist H (1988) Parameterization of condensation and associated clouds in models for weather prediction and general circulation simulation. In: Schlesinger ME (ed) Physically based modelling and simulation of climate and climatic change, vol 1. Kluwer, London, pp 433-461

Teixeira J (1999) Stable schemes for partial differential equations: the one-dimensional diffusion equation. $J$ Comput Phys 153:403-417

Teixeira J, Reynolds CA, Judd K (2007) Time step sensitivity of nonlinear atmospheric models: numerical convergence, truncation error growth, and ensemble design. J Atmos Sci 64:175-189

Wheeler M, Kiladis GN (1999) Convectively coupled equatorial waves: analysis of clouds and temperature in the wavenumberfrequency domain. J Atmos Sci 56:374-399

Williamson DL (1996) Application of semi-lagrangian methods to climate simulation. In: Proceedings on semi-Lagrangian methods, ECMWF, United Kingdom. p 167 
Williamson DL (2008) Convergence of aqua-planet simulations with increasing resolution in the Community Atmospheric Model, Version 3. Tellus A 60:848-862

Williamson DL, Olson JG (2003) Dependence of aqua-planet simulations on time step. Quart J R Meteor Soc 129:2049-2064

Xie P, Arkin PA (1996) Global precipitation: a 17-year monthly analysis based on gauge observations, satellite estimates, and numerical model outputs. Bull Am Meteor Soc 78:2539-2558
Zhang GJ, McFarlane NA (1995) Sensitivity of climate simulations to the parameterization of cumulus convection in the CCGCM. Atmos Ocean 33:407-446

Zhang M, Lin W, Bretherton CS, Hack JJ, Rasch PJ (2003) A modified formulation of fractional stratiform condensation rate in the NCAR community atmospheric model CAM2. J Geophys Res 108(D1):4035. doi:10.1029/2002JD002523 